Ser na Psicologia: diálogos sobre a profissão

\title{
A DIFERENÇA QUE NOS UNE: O MÚLTIPLO SURGIMENTO DA PSICOLOGIA
}

Arthur Arruda Leal Ferreira

\section{INTRODUÇÃo}

O lugar de onde foi pensada esta palestra vem da pluralidade de uma experiência didática, de um percurso através de boa parte da grade didática da psicologia: Psicologia Geral (para os cursos de psicologia, história, serviço social, pedagogia, nutrição, odontologia e enfermagem), História da Psicologia, Behaviorismo, Gestaltismo, Psicologia da Percepção, Psicologia do Desenvolvimento, Psicologia da Aprendizagem e Psicologia Social. A parir desta diversidade, e especialmente conectado com o viés da História da Psicologia, é que se tentará pensar o que seria "O Ser na Psicologia", tentando dar ensejo ao diálogo proposto sobre a nossa profissão.

Pensar o que seria o "Ser" na Psicologia sempre nos conduz a nos encontramos nos limites do "Não-Ser", na dúvida do que se é. Não apenas pela polissemia do conceito, mas por poder ser tragado a cada momento pelas ciências naturais (como a neurofisologia e a biologia), pelas ciências sociais (como a sociologia e a antropologia), pelo senso comum, pela religião, as técnicas de governo e de auto-ajuda. A dúvida de "Não-Ser" não é periférica, como se pudesse haver uma região central do Ser de onde tudo o mais fosse puro acidente. Disputa-se entre as psicologias este suposto centro, esta hegemonia do Ser, ora numa disputa encarniçada, ora em alianças estratégicas entre profissionais. Como se a psicologia fosse no seu conjunto uma confederação de virtualidades ou possibilidades de Ser. Talvez algumas questões sirvam para ilustrar a Babel em que nós psicólogos nos encontramos na busca do nosso Ser:

1) Por que existem tantas psicologias (sistemas, projetos, escolas, teorias, hipóteses, orientações práticas, marcas autorais etc.), não concordando os psicólogos nem quanto à definição da psicologia?

2) Por que não ocorre, como nas ciências naturais (ou duras), o predomínio de um projeto científico sobre os demais?

3) Por que não ocorre, ao menos, a refutação de uma das tendências presentes no espaço psicológico, em que esta se mostre falsa, ou ao menos ineficaz?

4) Por que neste espaço proposições com condições e conseqüências tão opostas se sustentam?

5) Por que estas contradições se mantêm, ainda que o apelo à investigação empírica seja tão rigoroso e extenso como nas ciências naturais?

6) Por que as psicologias, mesmo as que buscam uma fidelidade mais estrita aos cânones das ciências naturais (seus métodos, seus modelos), não são sempre reconhecidas por estas, nem pelas epistemologias que as estudam? 
7) Por que as práticas psicológicas mais diversas, positivadas em investigações empíricas das tendências mais díspares, se sustentam, ainda que apontem para as técnicas e finalidades mais divergentes?

8) Por que todas psicologias conseguem colher provas empíricas, práticas e argumentativas contra as demais e a favor de si?

9) Por que os psicólogos não resolvem estes impasses ao tomar conhecimento de novas epistemologias, modelos e metodologias científicas, sendo que em nenhum outro saber se discute tanto sobre epistemologia, metodologia, ou modelos científicos?

Enfim:

10) Por que a psicologia tende a satisfazer seu público, dividir cientistas, filósofos e epistemólogos, e conduzir as suas partes ao conflito?

Simplificando ao extremo, duas abordagens são possíveis na tentativa de responder a essas questões. A primeira, a epistemológica, buscará, através de uma abordagem normativa, distinguir na história das ciências o progresso na direção de uma verdade, ou, ao menos, um maior distanciamento dos erros e ilusões primeiras. Já a segunda abordagem não tentará separar opinião de conhecimento, entendendo a verdade não como um ideal regulador dos saberes, mas como efeito de uma determinada configuração histórica, no jogo de suas possibilidades. Por conta das dificuldades da epistemologia de dar conta desta situação, apelando para uma solução futura e ideal, segunda abordagem será adotada. Dentro desta perspectiva dois modelos serão propostos para explicar esta dispersão do campo psicológico: um modelo sincrônico e descritivo, a Máquina de Múltiplas Capturas e um outro dicrônico que explicaria historicamente o primeiro, o das Modernidades Cindidas. Estes modelos serão expostos a partir de alguns tópicos sintéticos.

\section{Máquina de Múltiplas Capturas}

1. Algumas hipóteses tem sido lançadas para explicar esta dispersão da psicologia, como:
a) A imaturidade das ciências humanas (a ser redimida em um futuro próximo).
b) A complexidade dos fenômenos humanos.
c) A existência de uma unidade insuspeita: o ser humano em si, que se esconderia por detrás das teorias, que seriam complementares na sua abordagem.

2. Estas teses são problematizáveis pelas seguintes razões:

a) Existem saberes mais recentes (a quântica, por exemplo) que já alcançaram rapidamente o reconhecimento como parte integrante da ciência.

b) Em alguns saberes sobre objetos complexos (o clima, por exemplo) não há o debate sobre o seu objeto de estudo. 
c) Uma boa parte dos sistemas psicológicos almeja, a partir de princípios simples, dar conta de todos os fenômenos humanos, restando saber quem é o ser humano que permanece subjacente às teorias: não seria ele também construído por um saber?

3. Uma possível explicação sobre esta dispersão pode-se encontrar no fato dos sujeitos deste conhecimento serem ao mesmo tempo os seus objetos: os indivíduos humanos em busca do conhecimento de si.

4. Portanto, as diversas psicologias se efetivam, não porque revelem diversos aspectos do fenômeno humano em sua complexidade, mas porque produzem-nos através dos diversos modos de ser humanos.

5. Produzem-nos, em primeiro lugar pelo seu suposto poder de ser ciência, detendo portanto o capital moderno de dizer nossa verdade.

Produzem-nos, em segundo lugar, porque suas doutrinas e técnicas estão em continuidade com outras práticas sociais historicamente gestadas.

6. As psicologias extraem a sua força do seu cruzamento entre aparatos científicos (métodos, modelos formais e conceitos extraídos de outras ciências) e práticas sociais solidificadas ao longo da história.

7. Esta força explica de igual modo a sua diversidade, pois as psicologias resultam do cruzamento de diversos modelos científicos com práticas sociais, gestando a partir deste duplo poder diversas formas de subjetividade, de ser humano

\section{Modernidades Cindidas}

1. Contudo, este curto-circuito que gesta e marca a dispersão das psicologias tem uma história, e esta tem a sua condição de possibilidade na tentativa moderna de separação entre um domínio de seres naturais e outro de seres humanos, como especifica Bruno Latour (1994); sem a cisão entre estes dois domínios não haveria a múltipla possibilidade de recombiná-los.

2. Se Latour examina prioritariamente como os seres naturais passam a ser representados nos parlamentos e fóruns humanos (como os Partidos Verdes e os concílios sobre o clima), resta dar conta de como os seres humanos são representados nos laboratórios científicos e objetivados como os demais seres naturais, sendo este exame conduzido por Michel Foucault (1996) em As Palavras e as Coisas.

3. Neste livro Foucault entende que esta abordagem do Homem como Ser Empírico (objeto natural) só foi possível na Modernidade, graças à superação de um modelo de conhecimento Clássico, o da Representação, que buscava ordenar os seres em ordens ideais; somente na Modernidade é que os seres foram abordados em sua profundidade empírica e histórica. 
4. O homem, descortinado somo Ser Empírico (objeto natural) pela Economia, Biologia e Filologia é reduplicado em Ser Transcendental (sujeito fundamentante) por uma série de filosofias antropológicas como as Dialéticas, o Positivismo e a Fenomenologia: é do cruzamento destas ciências empíricas do homem com as filosofias antropológicas é que nasceriam as ciências humanas como a psicologia.

5. Contudo a cisão Homem X Natureza (ou Homem Empírico X Transcendental) não representa a única tentativa moderna de separação entre domínios: podemos ver uma série de experiências modernas de dissociação, como a que se opera entre corpo e mente (VIDAL, 2002), loucura e razão (FOUCAULT, 1961/1972), infância e idade adulta (ARIÈS, 1979), domínio privado e público (ELIAS, 1989; BERGER, 1985), indivíduo soberano e disciplinado (FOUCAULT, 1976/1982) e subjetividade empírica e transcendental (FIGUEIREDO, 1995).

6. O termo modernidade se refere em sua acepção original à atualidade, e no levantamento de vários objetos históricos atuais, percebe-se em muitos destes esta experiência de cisão, cada qual remetendo a um conjunto de acontecimentos singulares.

7. Esta junção entre Homem e Natureza (ou entre Homem como Ser Empírico e Homem como Ser Transcendental) produz um Transcendental (fundamento inconsciente) na nossa experiência interior e uma Norma (determinação/ controle) para a nossa liberdade política.

8. Apesar de todas as cisões serem relevantes, duas se encontram de modo mais constante neste múltiplo bordado humano das psicologias: indivíduo soberano e disciplinado e subjetividade empírica e transcendental (as demais cisões estão presentes de forma variável).

9. Por serem mais constantes na experiência de hibridação que constitui as psicologias, as cisões entre Homem X Natureza, Indivíduo soberano X disciplinado, e Subjetividade empírica X transcendental servem como coordenadas para se compreender a pluralidade de misturas que habitam o campo psicológico.

10. Assim, toda psicologia reúne no plano do conhecimento um conceito empírico de uma outra ciência (em geral das ciências duras ou naturais) a uma determinada concepção transcendental do ser humano.

11. Assim, toda psicologia reúne no plano ético um modo de relação entre o nosso sujeito empírico (as nossas experiências conscientes) com um sujeito transcendental (que é em geral um conceito natural); a maior parte das psicologias parte da nossa subjetividade empírica para a transcendental (posição metapsicológica), mas outras, como a behaviorista, negando a evidência da mente e da consciência (sujeito empírico) só a atingirão através de um conceito transcendental (posição parapsicológica). 
12. Assim, a maioria das psicologias no plano político (nas suas práticas) reúnem um modo de abordar o indivíduo tanto como ser autônomo e livre (soberano), como sujeito a ser disciplinado e controlado: algumas psicologias, mesmo que privilegiem a autonomia do ser humano, remetem-na a uma norma natural; outras, ainda que tentem disciplinar os indivíduos, fazem-no de modo a favorecer o seu autocontrole autônomo.

Contudo, para o que aponta esta diversidade descrita? Deve-se insistir que esta questão não remete mais para uma solução epistemológica. A recusa a esta solução não se deve apenas a uma escolha pessoal, mas pelo fato de que ela atua na direção inversa de sua busca por unidade: os modelos científicos e as orientações metodológicas importadas das ciências naturais são bem diversos, dando ensejo a escolas e sistemas bem diferentes. De mais a mais, esta aplicação do receituário científico não garante a verificação, ou ao menos a superação de um projeto psicológico em prol dos demais; apenas reforça a tensão no interior deste saber em que cada orientação se arma das provas que ela mesmo se dá contra as demais. Descartada a alternativa epistemológica, restam as abordagens éticas, políticas e até estéticas: que formas de vida, que modos de subjetivação são gerados na psicologia? Não se busca aqui apenas uma psicologia que se nutra desta pluralidade, considerando a história com o seu poder de produzir ficções, mas também aquela que faculta o pluralismo em suas práticas, que nos desenraíze de nós mesmos. E aqui os exemplos são muitos: A psicologia histórica de Ignace Meyerson e Jean-Pierre Vernant (1990) poderia ser tomada como exemplar, especialmente se esta se voltasse para a própria psicologia enquanto obra histórica do espírito, na qual se expressariam as funções psicológicas (percepção, pensamento, memória, etc), igualmente datadas e modificadas dialeticamente pela própria presença da "obra psicológica". No cenário brasileiro pode ser observado o esforço de cunho mais filosófico de se pensar numa clínica, e mesmo uma psicologia, de cunho mais processual e atenta às modificações da subjetividade contemporânea. Esta tem sido a marca de grupos como os núcleos de Subjetividade e de Singularidade da Psicologia Clínica da PUC de São Paulo, e do grupo Sujeito \& Subjetividade da UFF/UFRJ, no Rio de Janeiro, isto sem deixar de citar linhas de pesquisa sobre a subjetividade contemporânea desenvolvidas por pesquisadores como Jurandir Freire Costa (1994) e Benílton Bezerra do IMS/UERJ. Em todas as vertentes destes grupos, nota-se a busca de outras parcerias que esvaziem a aliança epistemológica tradicional firmada pela psicologia desde suas origens. Em todas estas não apenas se acolhe, mas se gesta a nossa pluralidade, sem que se vislumbre a dissolução nas diferenças que nos constituem. 


\section{REFERÊNCIAS}

ARIÉS, P. História social da criança e da família. Tradução de Dora Flaskman. Rio de Janeiro: J. Zahar, 1979.

BERGER, P. Para uma compreensão sociológica da Psicanálise. Tradução de Jane Russo. In: FIGUEIRA, S. (Org.) Psicanálise e Ciências Sociais. Rio de Janeiro: Francisco Alves, 1985. p. 11-26.

COSTA, J. F. Redescrições em Psicanálise. Rio de Janeiro: Relume Dumará, 1994.

ELIAS, N. El proceso de la civilización. Tradução de Ramón García Cortarelo. Mexico: Fondo de Cultura Económica, 1989.

FIGUEIREDO, L. C. M. Os lugares da psicologia. In: . Revisitando as psicologias. São Paulo: Vozes/Educ, 1995. p. 13-33

FOUCAULT, M. A História da Loucura (1961). Tradução de José Teixeira Coelho Netto. São Paulo: Perspectiva, 1972.

. As palavras e as coisas. Tradução de Antonio Ramos Rosa. Lisboa: Portugália, 1966.

- Soberania e disciplina (1976). Tradução de MACHADO, R. \& OLIVEIRA, M. T. In: MACHADO, R. (Org.). Microfisica do Poder. Rio de Janeiro: Graal, 1982. p. 179-191.

LATOUR, B. Jamais fomos modernos. Tradução de Carlos Irineu da Costa. Rio de Janeiro: Editora 34, 1994.

VERNANT, J. P. El individuo en la ciudad. Tradução de Irene Agoff. In: Sobre el individuo. Barcelona: Paidós, 1990, p. 25-46.

VIDAL, F. L'histoire et les enjeux des neurosciences: l'avènement du «sujet cérébral» au $\mathrm{XX}^{\mathrm{e}}$ siècle. (Programa de pesquisa apresentado para concurso no CNRS), 2002. 